\title{
Elicitation of expert knowledge on controlling Salmonella in the pork chain
}

\author{
Monique A. van der Gaag ${ }^{1,2}$ and Ruud B.M. Huirne ${ }^{2}$ \\ ${ }^{1}$ Research Institute for Animal Husbandry, P.O. Box 2176, 8203 AD, Lelystad, the Netherlands \\ ${ }^{2}$ Wageningen University, Farm Management, Hollandseweg 6, 6706 KN, Wageningen, the Netherlands; \\ e-mail: Monique.vanderGaag@alg.abe.wau.nl
}

\begin{abstract}
Salmonella is one of the most important risks for food safety, and pork is one of the sources of human salmonellosis. A chain approach is essential to reduce Salmonella in pork products. A survey was carried out among Dutch and Danish experts in the field of Salmonella to evaluate the entire pork supply chain. The aims of the survey were to determine and rank possible management interventions (such as adjusted or new procedures, technical adjustments and control measures), and to estimate the details of the course of infection and contamination. An additional objective was to compare the opinions of experts from different countries and different backgrounds. The two stages in which it was expected that management interventions to improving food safety with respect to Salmonella in pork would be most effective were the the finishing stage (by preventing the spread of Salmonella within the farm) and the slaughtering stage (by preventing cross-contamination). The differences in the opinions of respondents from different backgrounds were mainly reflected by the relative importance they attached to the specific management interventions. For instance, the Danish respondents attached more importance to the purchase of Salmonella-free piglets in the finishing stage and to logistic slaughter. Respondents with a research background seemed to attach most importance to interventions that were also presented in recent literature, such as feeding non-heated grain to finishing pigs. For issues in which multiple stages of a supply chain are involved, a solid basic knowledge about the conditions per stage with respect to the issue is necessary.
\end{abstract}

Keywords: food safety, pigs, survey, chain approach

\section{Introduction}

A supply chain consists of stages that fulfil, directly or indirectly, customer requests; and each stage of the supply chain performs different processes and interacts with other stages of the supply chain (Chopra and Meindl, 2001). A major issue in food supply chains is ensuring food safety. Food safety risks can be chemical, physical or microbiological, the latter being the most important one. The bacteria Salmonella and Campylobacter are the major agents for bacterial food-borne zoonoses, which are diseases that can be transferred from animals to humans. In the Netherlands 25\% of the annual 50,000 human cases of salmonellosis are caused by serotypes that occur in pigs (Van Pelt and Valkenburgh, 2001). Over 90\% of the pig farms have pigs that were serologically positive for Salmonella (Van der Wolf, 2000), so it is very likely that every Dutch slaughterhouse will receive contaminated pigs. At the slaughterhouse, the average prevalence of contaminated carcasses is estimated at about 2\% (Swanenburg, 2000). In 2000, 18.8 million pigs were slaughtered in the Netherlands (Anon., 2001), which indicates that in 2000 over 350,000 contaminated carcasses entered the food chain.

Concerning food safety issues like Salmonella contamination, which can occur in each stage of the supply chain, all participants have to be involved (e.g. Berends et al., 1998; Lammerding and Fazil, 2000). One stage cannot solve the food safety risk of pork with respect to Salmonella. Furthermore, the EU approach is to take the necessary preventive interventions at all the appropriate stages in the supply chain during production and processing in order to avoid contamination (Anon., 1997). Besides the shortage of compiled knowledge of possible management interventions in the entire pork supply chain, there is a lack of knowledge about the course of infection and contamination. To overcome these shortcomings, a survey was carried out among experts in the field of Salmonella covering the entire pork supply chain.

The first aim of the survey was to determine and rank management interventions to reduce introduction and spread of Salmonella in the pork supply chain. The second aim was to compare the opinions of experts from different countries and backgrounds to gain insight into the extent of agreement. This insight may play a role in the future control of Salmonella in the pork supply chain and in the preferred co-operation between stages in the chain to improve public health.

The outline of the paper is as follows: Section 2 describes the background of the pork supply chain. Section 3 concentrates on the design of the survey, and Section 4 on 
the type of analysis used. Section 5 presents the results related to management interventions in the pork chain. Section 6 presents the results related to the course of infection and contamination and Section 7 provides the conclusions and a discussion of the results.

\section{The pork supply chain}

\section{Introduction to the pork supply chain}

Within an expanding market, production and efficiency in food supply chains increase through specialisation and concentration. In the pork supply chain primary farms are highly specialised in multiplying or finishing to maximise the product output. The number of primary farms was halved in the last decade from 29,000 pig farms in 1990 to 14,500 pig farms in 2000 , although the number of pigs decreased by only $6 \%$ from 13.9 million to 13.1 million pigs (CBS, 2002). Nowadays markets have become saturated and firms in the post harvest stages of the pork supply chain are merging to survive in a market with global competition. To subsist it is important to offer a differentiated package of products to retails and consumers. For specific market and production characteristics, such as assuring food safety in the supply chain, joint investments and co-operation among stages are needed (Ziggers and Trienekens, 1999). Enforcing the implementation of performance and process standards to ensure food safety, for example, is increasingly related to meta-management systems at all levels of a chain (Reardon and Farina, 2002). It is unlikely that a supply chain will operate effectively unless all participants are able to identify value both to themselves and to their customers (Christopherson and Coath, 2002). Especially with food safety issues like Salmonella contamination, which can occur in each stage of the supply chain, all participants have to be involved. In any case, before putting all kinds of management interventions and rules into practice, more insight is needed into what interventions are (expected to be) the most effective to improve the food safety of pork with respect to Salmonella. It is not possible to test all management interventions on a large scale in field studies, since such field studies are too costly and some interventions have not been applied yet in practice (Dijkhuizen and Morris, 1997). In the literature the focus is mostly on one single stage in the chain (e.g. Stege et al. 2001; Isaacson, 1999a,b; Davies and Wray, 1997) or on one single aspect of Salmonella (e.g. Jørgensen et al. 1999; Van Winsen, 2001). So, partial information on Salmonella is available, but a complete chain approach is lacking.

\section{Salmonella in the pork supply chain}

Salmonella is ubiquitous in nature and, as stated before, it can be introduced and spread in each stage of the pork chain. Pigs can come in contact with the bacteria at the former stage or through external sources, such as people, rodents, feed, water, etc. Once introduced, the bacteria can be spread in the farm or firm and go via the entire pork chain to the consumer. A certified Salmonella-free meat product is hard to attain (decontamination of meat is not allowed in the EU), but a certified production process to prevent Salmonella is an effective strategy to fulfil the customers' request/demands.

To clarify the pork supply chain, this chain will be described briefly. The pork supply chain consists of several stages. Figure 1 shows the different stages in the chain: breeding, multiplying, finishing, transportation, slaughtering (lairage and slaughter), processing, retailing and consuming. All stages have relations with partners that are linked to the main food supply chain, such as feed companies and service suppliers. The possible management interventions of the stages multiplying through slaughter are discussed separately in the survey. These stages produce the basic end product of the pork chain, which is a chilled carcass.

The primary stages (breeding through finishing) take place for the most part in specialised family farms. The breeding stage produces sows for the multiplying stage. In the multiplying stage finishing pigs are produced, and then sold for the finishing stage at an average live weight of 25 kilograms. Multiplying and finishing may take place on the same farm. In the finishing stage pigs are fattened to a live weight of approximately 110 kilograms. Specialised private transport companies in the transportation stage arrange the transportation of the pigs from the finishing farm to the slaughterhouse. At the slaughterhouses, pigs stay in the lairage (holding pens) for a few hours to calm down after the transport. At the slaughtering stage pigs are slaughtered. The next day the carcass is processed further and transported to retailers, from where it is sold to the consumer.

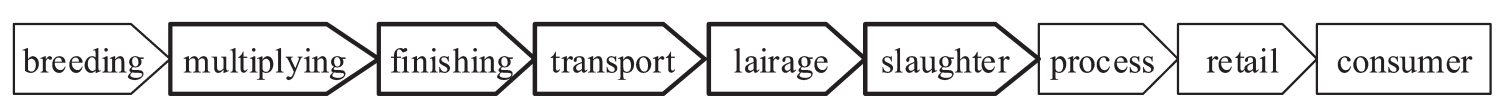

Figure 1. Schematic structure of the pork supply chain. The bold outlined stages are discussed separately in the survey. 


\section{The design of the survey}

In this research, an expert was defined as someone who is involved in the pork supply chain and is known for his/her knowledge about Salmonella in pigs and/or pork. Based on this definition, a list was compiled of experts in the Netherlands and Denmark. People on the list were asked whether they knew others who are also known for their knowledge about Salmonella. The design of the Danish pork supply chain is more or less similar to the Dutch situation. Moreover, Denmark has had a surveillance and control programme for Salmonella since 1995 (Alban et al., 2002). The recommendations by Summerhill and Taylor (1992) were followed in designing and distributing the survey. In total 80 experts were invited to participate in the survey; 48 from the Netherlands in March 2001 and 32 from Denmark in July 2001. Two weeks after the invitation, the surveys were sent to 75 experts who were willing to complete the survey. After 3 to 4 weeks a reminder was sent.

The survey consisted of five parts, categorised in Table 1 and described in detail in the next section.

The five parts of the survey:

A) General. Questions related to the background and the field of knowledge of the respondent.

B) Management interventions. Questions related to the (relative) importance of management interventions per stage. The stages multiplying, finishing, transportation, lairage and slaughtering were discussed separately. For each stage ten to fifteen management interventions were given based on articles in literature that concerned details of the pork supply chain (e.g. Stege et al., 2001; Isaacson, 1999a,b; Davies and Wray, 1997; Jørgensen et al., 1999; Van Winsen, 2001). The categories of management interventions are described in Tables 3 to 7 in Section 5. Respondents could add additional interventions. The respondents were asked to distribute 100 points over the interventions to indicate the (relative) importance of each individual intervention.
C) Statements. 26 statements related to Salmonella in the pork supply chain were formulated (see Appendix). Some statements were included to test the consistency of the respondents' answers (to test whether answers to these statements corresponded with answers given in parts $\mathrm{D}$ and $\mathrm{E}$ ). The respondent was asked to indicate whether he/she agreed with the statement or not. Twenty-six statements were presented to the Dutch respondents and a selection of twelve statements was presented to the Danish respondents. After conducting the Dutch survey, respondents indicated that some statements were too obvious and thus decreased the respondents' motivation to complete all statements. Therefore, a selection was made for the Danish survey.

D) Course of infection in finishing pigs. First, an infected pig was defined as a pig that had been in contact with a large enough dose of Salmonella bacteria that the pig itself became infectious, i.e. it started shedding Salmonella itself. Eight variables about the course of infection were included in part $\mathrm{D}$ and for each variable a three-point estimation was requested, i.e. the respondents were asked to estimate the minimum value, most likely value and maximum value for each variable. The eight variables were:

D1 duration of seroconversion period

D2 duration of infectious period (the pig is serologically negative and fed dry-pelleted feed)

D3 duration of infectious period (the pig is serologically negative and fed acidified feed)

D4 duration of infectious period (the pig is serologically positive and fed dry-pelleted feed)

D5 duration of carrier period

D6 period to become serologically negative after having become positive

D7 infection rate in a group of 100 serologically negative pigs

D8 infection rate in a group of 100 serologically positive pigs.

E) Course of contamination of carcasses at the slaughterline. For the importance of contamination at the

Table 1. The five parts of the survey.

\begin{tabular}{llll}
\hline Part & Subject & Motivation & Response possibilities \\
A & General & Categorise respondents & Country and background \\
B & Management interventions & Ranking interventions & Distribution of 100 points \\
C & Statements & Compare categories of respondents & Agree / Do not agree / Do not know \\
D & Course of infection & Compare categories of respondents & Three point estimation \\
E & Course of contamination & Compare categories of respondents & Three point estimation \\
\hline
\end{tabular}


slaughterline a three-point estimation was requested for four variables. The four variables were:

E1 probability that a bacteria-free carcass will become contaminated, if one of the preceding carcasses is contaminated with Salmonella

E2 probability that a bacteria-free carcasses will become contaminated if four preceding carcasses are contaminated

E3 probability that an infected pig will end up as a bacteria-free carcass

E4 probability that a bacteria-free pig will end up as a contaminated carcass if half the pigs slaughtered that day are contaminated.

\section{Analysis}

The respondents were classified by country of origin (the Netherlands and Denmark) and by background (Animal production, Retail \& Policy and Research). The class “Animal production" includes respondents working for slaughterhouses or in the feed industry and people from (organised) interest groups. The class "Retail \& Policy" includes respondents working for retail, government and product boards, and the class "Research" includes respondents working for research institutes and universities. The management interventions were classified per stage into five to seven categories. The Kruskal Wallis test was used to test the difference in specific interventions and categories of interventions between groups of respondents. Per statement the percentage of respondents who agreed was computed and the differences between groups of respondents were calculated. For all three-point estimations of the 12 variables, the mean and standard deviations were calculated per group.

The response rate was 59\%. Seven percent of the respondents indicated that they did not want to complete the survey, because they did not have the specific knowledge, they were not interested or they could not find time due to the outbreak of Foot-and-Mouth Disease in the Netherlands. In total 39 experts completed the survey (Table 2).

A response rate of over $50 \%$ is fairly good for a mail survey. Some questions were not or incompletely answered, which is not unusual. Most respondents who did not or incompletely answered a question indicated that they did not have the knowledge to answer the question. The survey may have been too long for some respondents, as completing it took about one hour.

It was not possible to test differences between groups of respondents for the statements and the three-point estimations, since only one or a few respondents answered these questions.
Table 2. Number of respondents per country and background.

\begin{tabular}{llcc}
\hline & the Netherlands & Denmark & Total \\
& & & \\
Animal production & 8 & 4 & 10 \\
Retail \& Policy & 7 & 10 & 11 \\
Research & 8 & 16 & 39 \\
Total & 23 & 16 & \\
\hline
\end{tabular}

\section{Results: Management interventions in the pork chain}

\section{Multiplying and finishing: management interventions and statements}

In the multiplying stage, the emphasis was on the prevalence of Salmonella in piglets of 25 kilograms, while in the finishing stage the emphasis was on the prevalence of Salmonella in finishing pigs of $110 \mathrm{~kg}$.

As shown in Table 3, the most important category of management interventions was related to feed supply. In particular, the use of acidified or fermented feed and buying certified Salmonella-free feed were mentioned. Whereas 43\% of the Danish respondents also indicated that meal feed and non-heated grain were effective management interventions, none of the Dutch respondents did so. From the survey it did not become clear whether the feeding interventions in the multiplying stage should be applied to piglets, sows or both. The second category of interventions was related to hygiene to prevent the spread of Salmonella on the farm. The interventions mentioned were: using separate materials such as brooms and boots per barn or compartment, cleaning and disinfecting compartments for piglets after each period and separating housing facilities for sows and weaned piglets. Implementing a new feeding strategy and using separate housing facilities concern only the multiplying stage. Purchasing certified Salmonella-free sows also has an effect on the management of the former stage (breeding), and information exchange is essential. There was a significant difference between responses from the Netherlands and Denmark in the category hygiene related to introduction in the multiplying stage. The Danish respondents attached more importance to purchasing Salmonella-free piglets in the finishing stage.

There were no significant differences among the respondents from different backgrounds. 
Table 3. Distribution of 100 points over management interventions in the multiplying and finishing stages.

\begin{tabular}{|c|c|c|c|c|c|c|}
\hline \multicolumn{7}{|l|}{ Multiplying stage } \\
\hline Interventions related to: & $\begin{array}{l}\text { total } \\
\mathrm{N}=34\end{array}$ & $\begin{array}{l}\text { Netherlands } \\
\mathrm{n}=20\end{array}$ & $\begin{array}{l}\text { Denmark } \\
n=14\end{array}$ & $\begin{array}{l}\text { Animal prod. } \\
n=10\end{array}$ & $\begin{array}{l}\text { Retail \& Policy } \\
n=10\end{array}$ & $\begin{array}{l}\text { Research } \\
n=14\end{array}$ \\
\hline Feed46 & 41 & 52 & 35 & 50 & 51 & \\
\hline Hygiene to prevent spreading & 16 & 19 & 13 & 19 & 13 & 16 \\
\hline Salmonella-free sows & 14 & 13 & 16 & 15 & 17 & 13 \\
\hline Hygiene to prevent introduction & 13 & $17^{*}$ & $8^{*}$ & 16 & 11 & 12 \\
\hline Housing sows and piglets & 10 & 9 & 11 & 15 & 9 & 8 \\
\hline Other & 2 & 2 & 0 & 1 & 0 & 1 \\
\hline Total & 100 & 100 & 100 & 100 & 100 & 100 \\
\hline \multicolumn{7}{|l|}{ Finishing stage } \\
\hline Interventions related to: & $\begin{array}{l}\text { total } \\
\mathrm{N}=34\end{array}$ & $\begin{array}{l}\text { Netherlands } \\
n=20\end{array}$ & $\begin{array}{l}\text { Denmark } \\
n=14\end{array}$ & $\begin{array}{l}\text { Animal prod. } \\
n=9\end{array}$ & $\begin{array}{l}\text { Retail \& Policy } \\
n=8\end{array}$ & $\begin{array}{l}\text { Research } \\
n=17\end{array}$ \\
\hline Feed38 & 33 & 46 & 31 & 32 & 45 & \\
\hline Hygiene to prevent spreading & 24 & 28 & 19 & 29 & 24 & 22 \\
\hline Salmonella-free piglets & 15 & $12^{*}$ & $20 *$ & 13 & 13 & 18 \\
\hline Hygiene to prevent introduction & 8 & 9 & 6 & 9 & 7 & 7 \\
\hline Management $^{1}$ & 8 & 10 & 6 & 8 & 13 & 6 \\
\hline Other & 5 & $8 *$ & 1 * & 4 & $12^{*}$ & $2^{*}$ \\
\hline Batch production & 2 & 1 & 2 & 6 & 0 & 0 \\
\hline Total & 100 & 100 & 100 & 100 & 100 & 100 \\
\hline
\end{tabular}

1) E.g. climate control, strict protocol for visitors

*: $p<0.05$

Seven statements concerned the primary stages. The percentages of respondents who agreed are shown in Table 4. A part of the 12 statements for all respondents was linked with an analytical model (an epidemiological framework) about the course of a Salmonella infection in live pigs. This model is shown in Figure 2.

The model starts with a Salmonella-free pig (S1). If the pig becomes infected, it becomes infectious (I1) and after a while serologically positive (I2). When the pig stops shedding (i.e. it is no longer infectious) it can still carry bacteria in the intestines or lymphatic system, the so-called carrier stage (C). A carrier can become infectious again (I3) or become bacteriologically Salmonella free, but it remains serologically positive (S2). From state $\mathrm{S} 2$ the pig can become re-infected (I3) or become serologically negative (S1).

For two statements there was a difference $(\mathrm{p}<0.05)$ among respondents with different backgrounds Over $80 \%$ of the respondents with Research and Retail \& Policy backgrounds agreed that Salmonella does not affect the production results, whereas only $40 \%$ of the respondents with an Animal

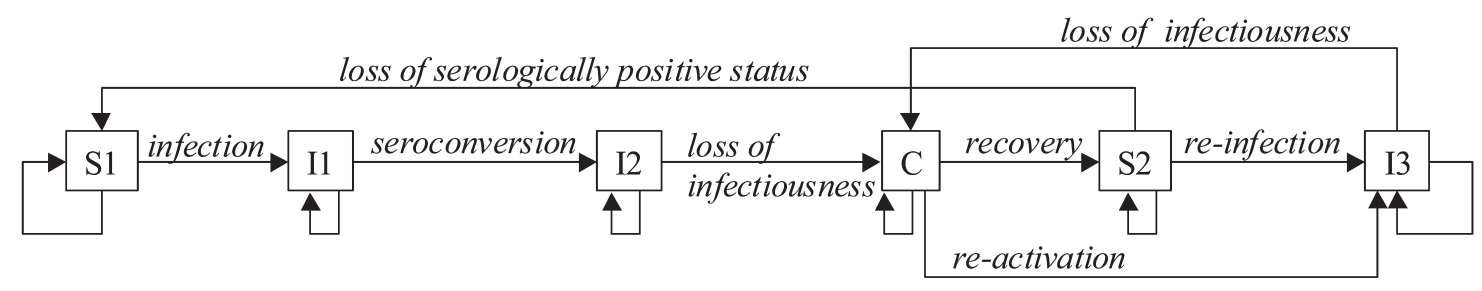

Figure 2. Course of a Salmonella infection in live pigs $(S=$ susceptible, $I=$ infectious and $C=$ carrier $)$. 
Table 4. Percentage of respondents who agreed with the statements with respect to primary stages (excluding the 'do not know' answers).

Statements

The course of a Salmonella infection can be represented as in Figure 2.

Salmonella infections do not influence the production results of finishing pigs.

After the infectious period a pig remains

(temporarily) a carrier, e.g. in intestines or

lymph nodes.

After the carrier period a pig remains

(temporarily) serologically positive.

Sensitivity to Salmonella does not depend on race, weight or sex.

After a pig has gone through an infection, it is less sensitive to a new Salmonella infection.

The infectivity of infectious pigs is about equal in states I1, I2 and I3.

$\%$ agreed

$92 *$

71

97

83 *

64

77 *

$30 *$

* Over $25 \%$ of the respondents indicated 'do not know'

production background agreed with this statement. This difference in perception is important for the willingness to invest in interventions and for the introduction of new regulations. Policymakers may not realise which side effects occur related to food safety issues in the primary stages. If participants in the primary stages expect that a higher prevalence of Salmonella at the farm leads to a decrease in production performance, their willingness to invest may be higher than if they do not expect a decrease in performance. This argument should result in an increase in willingness to invest. The statement that sensitivity to Salmonella does not depend on a pig's race, weight or sex includes three assumptions. About 57\% of respondents from Animal production and Retail \& Policy agreed, whereas $80 \%$ of the respondents from Research agreed. The respondents who did not agree indicated that they only did not agree with the assumption concerning weight (which is correlated to age). Pigs with a lower weight (i.e. younger pigs) are expected to be more sensitive to Salmonella infection than heavier (i.e. older) pigs.

The Dutch and Danish responses differed for two statements. All Danish respondents agreed with the statement 'After a pig has gone through an infection, it is less sensitive to a new Salmonella infection', and only $25 \%$ of the Dutch respondents agreed. The percentage of agreement with the statement "The infectivity of infectious pigs is about equal in states I1, I2 and I3' was also higher among the Danish respondents (38\%) than among the Dutch respondents $(14 \%)$.

\section{Management interventions during transportation}

The results of the distribution of 100 points over the management interventions are given in Table 5.

The three best interventions to reduce Salmonella introduction and spread during transportation according to the respondents were so-called "logistic transport", good hygiene, such as cleaning and disinfecting thoroughly after each ride, and transporting pigs from only one compartment of the finishing farm in one truck. In current practice, pigs from different pens and compartments are put together in

Table 5. Distribution of 100 points over management interventions in the transportation stage.

\begin{tabular}{|c|c|c|c|c|c|c|}
\hline Interventions related to: & $\begin{array}{l}\text { total } \\
\mathrm{N}=33\end{array}$ & $\begin{array}{l}\text { Netherlands } \\
n=21\end{array}$ & $\begin{array}{l}\text { Denmark } \\
n=12\end{array}$ & $\begin{array}{l}\text { Animal prod. } \\
n=10\end{array}$ & $\begin{array}{l}\text { Retail \& Policy } \\
n=7\end{array}$ & $\begin{array}{l}\text { Research } \\
n=16\end{array}$ \\
\hline Logistic transport & 21 & 22 & 20 & $25^{*}$ & $13^{*}$ & 22 \\
\hline Hygiene of truck & 18 & 16 & 22 & 18 & 22 & 16 \\
\hline One compartment / ride & 17 & 17 & 18 & 15 & 21 & 17 \\
\hline Fasting before transport & 10 & 11 & 7 & $15^{*}$ & 12 & $6 *$ \\
\hline Duration of transport $<2$ hrs & 10 & 9 & 12 & 8 & 6 & 13 \\
\hline Smooth-sided truck & 9 & 10 & 7 & 7 & 9 & 11 \\
\hline Quiet driving & 9 & 11 & 6 & 8 & 11 & 9 \\
\hline Other & 5 & 4 & 7 & 5 & 6 & 6 \\
\hline Total & 100 & 100 & 100 & 100 & 100 & 100 \\
\hline
\end{tabular}

*: $p<0.05$ 
one truck. Logistic transport means that trucks are only allowed to transport pigs from finishing farms with the same Salmonella status. So there can be specific trucks that may transport pigs from Salmonella-free farms. If realised, these interventions may have a drastic impact on the current operating procedures. Interventions that can be realised more easily are more patience during loading of pigs into the truck, quiet driving to the slaughterhouse to reduce stress, and fasting before transportation. Fasting is advised in most countries, since full intestines may pose a higher risk of puncturing during evisceration (e.g. Borch et al., 1996). Respondents from the Animal production group attached more importance to logistic transport than respondents from Retail \& Policy. They also attached more importance to fasting before transportation than respondents from Research $(\mathrm{p}<0.05)$. There were no significant differences between respondents from the Netherlands and Denmark.

The survey included one statement on transportation: 'All carrier animals become infectious during transportation (i.e. start shedding).' In total $14 \%$ of the respondents agreed with this statement. None of the respondents from Research agreed. They estimated that 35 to $60 \%$ of the carriers would become infectious during transport, depending on the manner of loading and the driving style of the driver.

\section{Management interventions in the lairage}

In the lairage, pigs from different finishing farms are collected in compartments that hold 20 tot 60 pigs each. The lairage is considered a risk factor for Salmonella infection and contamination, because pigs from different farms are collected together and the rough floors are hard to clean completely (Swanenburg, 2000; Rostagno et al., 2001). The most important management interventions according to the respondents are good hygiene, including more frequent cleaning and disinfecting, use of a construction that can be cleaned better, and rodent control. The second most important management intervention is logistic supply, which means that pigs from Salmonella-free herds are not delivered at the same time as pigs from herds with a different Salmonella prevalence. So pigs from Salmonella-free herds or from herds with a low prevalence are slaughtered on specific days or at the beginning of the day. The management interventions ranked third fourth and fifth were considered more or less equally important (see Table 6).

Respondents from the Research group attached more importance to a shorter duration in the lairage than respondents from Animal production $(\mathrm{p}<0.05)$ did. There were no significant differences between respondents from the Netherlands and Denmark.

The only statement on the lairage was "The greater the number of infectious pigs unloaded in the lairage, the higher the risk will be for susceptible pigs to become infected' Almost all respondents (97\%) agreed with this statement.

\section{Management interventions at the slaughterline}

According to the respondents, by far the most important management intervention for Salmonella at the slaughterline is logistic slaughtering. Several conditions have to be met for functional logistic slaughtering: a reliable monitoring system, farms with flexible delivery-strategies, clear transportation planning for delivering pigs and effective cleaning and disinfecting of trucks, lairage and slaughterline. If one or more of these conditions are not met, the effect of logistic slaughtering will be limited. So the co-operation of all stages is essential. The second-best management intervention was considered to be decontamination of the

Table 6. Distribution of 100 points over management interventions in the lairage.

\begin{tabular}{|c|c|c|c|c|c|c|}
\hline Interventions related to: & $\begin{array}{l}\text { total } \\
\mathrm{N}=32\end{array}$ & $\begin{array}{l}\text { Netherlands } \\
n=20\end{array}$ & $\begin{array}{l}\text { Denmark } \\
n=12\end{array}$ & $\begin{array}{l}\text { Animal prod. } \\
n=10\end{array}$ & $\begin{array}{l}\text { Retail \& Policy } \\
n=6\end{array}$ & $\begin{array}{l}\text { Research } \\
n=16\end{array}$ \\
\hline Hygiene of lairage & 29 & 30 & 27 & 30 & 31 & 28 \\
\hline Logistic slaughtering & 28 & 26 & 31 & 30 & 18 & 27 \\
\hline One group per compartment & 13 & 13 & 13 & 15 & 13 & 11 \\
\hline Closed compartment fences & 12 & 15 & 9 & 16 & 13 & 10 \\
\hline Shorter waiting period & 10 & 7 & 14 & $3 *$ & 10 & $14^{*}$ \\
\hline Slatted floors & 4 & 4 & 3 & 4 & 4 & 3 \\
\hline Other & 4 & 5 & 3 & 2 & 1 & 7 \\
\hline Total & 100 & 100 & 100 & 100 & 100 & 100 \\
\hline
\end{tabular}

$*$ : $p<0.05$ 
carcass at the end of the slaughterline. The European Committee is concerned about using such methods, which should not be applied to restore safety in a product that has been produced under poor hygiene conditions (Frerichs and Venturini, 2002).

Compared to the respondents from the Netherlands, the Danish respondents attached more importance to logistic slaughtering and no splitting of head and throat $(\mathrm{p}<0.05)$. The Dutch respondents attached more importance to additional cleaning of machines at the slaughterline. The Danish respondents often indicated that the temperature of the scalding tank should be set at least at $62^{\circ} \mathrm{C}$.

The respondents from the Retail and Policy group attached more importance to careful evisceration than respondents from the Animal production and Research groups $(\mathrm{p}<0.05)$.

Three statements dealt with the slaughterline (Table 8). There was only a difference in opinions between respondents from the Netherlands and Denmark concerning the third statement that 'An uncontaminated carcass reduces the contamination risk to the following carcass'. Of the Dutch respondents, $57 \%$ agreed and $89 \%$ of the Danish respondents agreed. With respect to food safety it is important to know the effect of the introduction of infected pigs and contaminated carcasses.

\section{Management interventions in entire chain from breeding through consumer}

To improve the food safety of pork with respect to Salmonella most effectively, it is necessary to know what interventions have to be taken in the entire chain. We asked for the five most effective interventions in the entire chain, regardless of the costs, to reduce the prevalence of Salmonella-positive carcasses.

If seven interventions were to be implemented, the combination of the following interventions was expected to be the most effective: use of acidified feed in primary stages, logistic slaughtering, decontamination of carcasses, extensive hygiene at the slaughterhouse and the primary stages, purchase of certified Salmonella-free piglets in the

Table 7. Distribution of 100 points over management interventions at the slaughterline.

\begin{tabular}{|c|c|c|c|c|c|c|}
\hline Interventions related to: & $\begin{array}{l}\text { total } \\
\mathrm{N}=30\end{array}$ & $\begin{array}{l}\text { Netherlands } \\
\mathrm{n}=28\end{array}$ & $\begin{array}{l}\text { Denmark } \\
n=12\end{array}$ & $\begin{array}{l}\text { Animal prod. } \\
n=7\end{array}$ & $\begin{array}{l}\text { Retail \& Policy } \\
n=10\end{array}$ & $\begin{array}{l}\text { Research } \\
n=13\end{array}$ \\
\hline Logistic slaughtering & 24 & $20 *$ & $31^{*}$ & 29 & 22 & 25 \\
\hline Decontamination & 15 & 16 & 13 & 19 & 13 & 14 \\
\hline Extended C\&D twice a day & 14 & 13 & 15 & 11 & 15 & 14 \\
\hline Careful evisceration & 12 & 14 & 9 & $9 *$ & $17^{*}$ & 10 \\
\hline Rectum packing & 9 & 8 & 10 & 7 & 8 & 10 \\
\hline No splitting of head and throat & 8 & $5^{*}$ & $13^{*}$ & 10 & 7 & 8 \\
\hline Additional C\&D slaughterline ${ }^{1}$ & 7 & $11^{*}$ & 0 * & 8 & $11^{*}$ & $3 *$ \\
\hline More distance between carcasses & 3 & 4 & 3 & 3 & 6 & 2 \\
\hline Other & 8 & 9 & 6 & 5 & 3 & 14 \\
\hline Total & 100 & 100 & 100 & 100 & 100 & 100 \\
\hline
\end{tabular}

${ }^{1}$ such as automatic rinsing of the saw blade after each carcass

${ }^{*}: p<0.05$

Table 8. Percentage of respondents who agreed with the statements with respect to the slaughterline, (excluding the 'do not know' answers). 
finishing stage and informing consumers on storing and preparation of meat. For the optimal performance of the entire pork supply chain with respect to human salmonellosis caused by pork, these interventions should be implemented.

The pork supply chain can be divided into four parts: consumption (consumer stage), processing and retail (boning through retail stages), harvest (transporting finishing pigs through the slaughtering stages) and preharvest (breeding through finishing stages). Respondents from the Animal production group assigned the greatest responsibility for contamination of the end product to the harvest part and respondents from Retail \& Policy assigned greatest responsibility to the pre-harvest part of the pork supply chain. Chain participants seem to put most stress on participants in stages other than their own.

\section{Results: Course of infection and contamination}

\section{Course of infection in finishing pigs}

The survey asked participants to estimate the duration of the five states of the epidemiological model (Figure 2). Between 12 and 22 respondents estimated the duration of the periods. The average and standard deviations are shown in Figure 3. Three respondents indicated that the most likely and the maximum duration of several states could last over a year. These estimations had a large influence on the averages. Since a finishing pig lives only six months, the estimations were maximised at 180 days.
The number of respondents varied among the questions. The number of respondents from the Animal production group was 3 to 4 and from Retail \& Policy the number was 1 to 2 . Therefore, a proper comparison among groups with respect to background was not possible. Estimations on the duration of these six states appeared to be difficult to make.

The infection rates of Salmonella in pigs in a group with susceptible pigs that were serologically negative or positive are shown in Figure 4. Twenty respondents answered questions related to these two groups, seven of whom noted no difference in infection rate between the serologically negative and positive pigs. The rest of the respondents estimated that the infection rate would be lower in the group with serologically positive pigs.

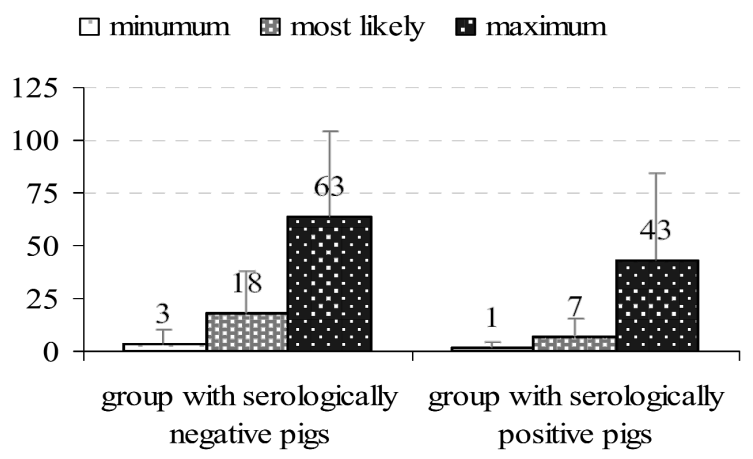

Figure 4. Number of pigs in a group of 100 pigs that can become infected by one infectious pig within a day.

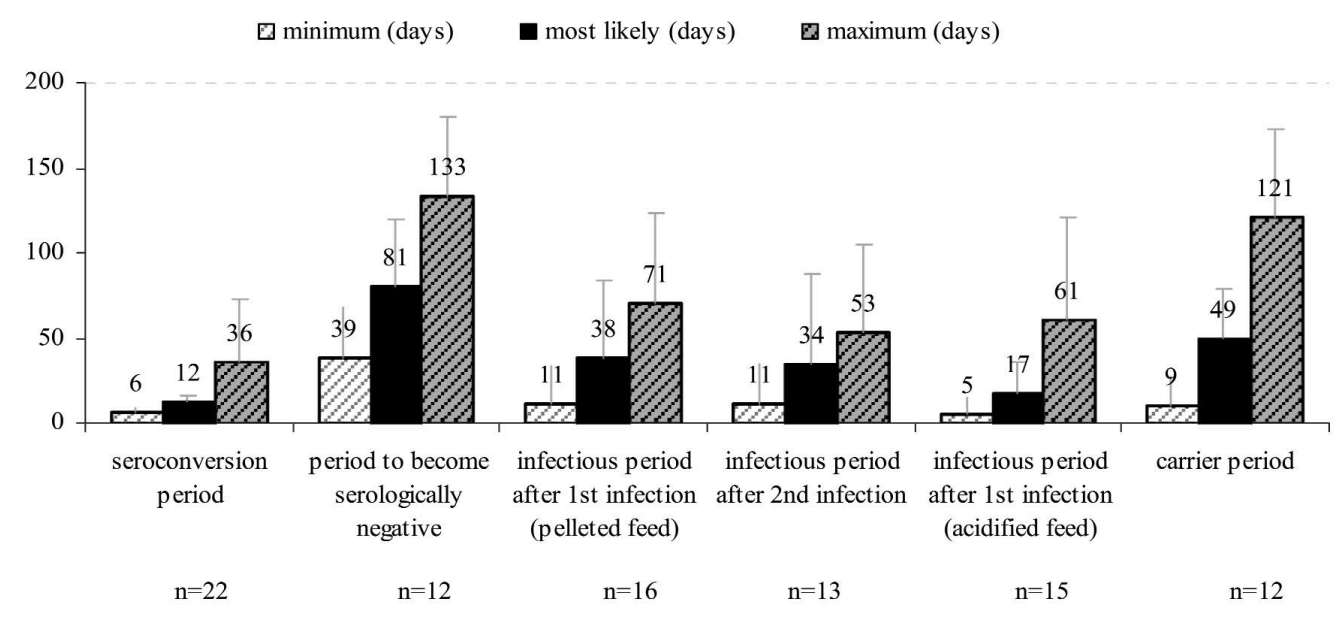

Figure 3. Averages and standard deviations of the estimation for the minimum, most likely and maximum duration of six states in the course of infection of Salmonella in finishing pigs. 
One statement was about the difference in sensitivity between serologically negative and positive pigs. In the estimation of the infection rate, the consistency of the participants' answers could be tested. About $30 \%$ of the respondents who answered both questions were not consistent. For instance, they did not agree with the statement that serologically positive pigs were less sensitive than serologically negative pigs, but they estimated that the infection rate in a group of serologically positive pigs was lower than in a group of serologically negative pigs. This inconsistency could mainly be observed in respondents with Animal production and Retail \& Policy backgrounds.

The Dutch respondents estimated the infection rates slightly higher than the Danish respondents did.

The average estimation of the most likely probability of introduction of Salmonella on finishing farms was $0.2 \%$ and the minimum percentage was $0.0 \%$. The maximum percentage varied among the groups. The overall average for the maximum percentage was $10 \%$. The respondents from Animal production estimated the risk at $22 \%$, which was much higher than those from Research with $7 \%$ and Retail \& Policy with $1 \%$.

\section{Contamination at the slaughterline}

All respondents agreed that the number of Salmonella-free carcasses that can be contaminated increases as the number of contaminated carcasses increases (Figure 5). The estimation of the maximum number of carcasses varied between 1 and 1000 carcasses.

The results show that the knowledge about the course of contamination is limited. Nevertheless, knowledge about the course of contamination is essential to improve the

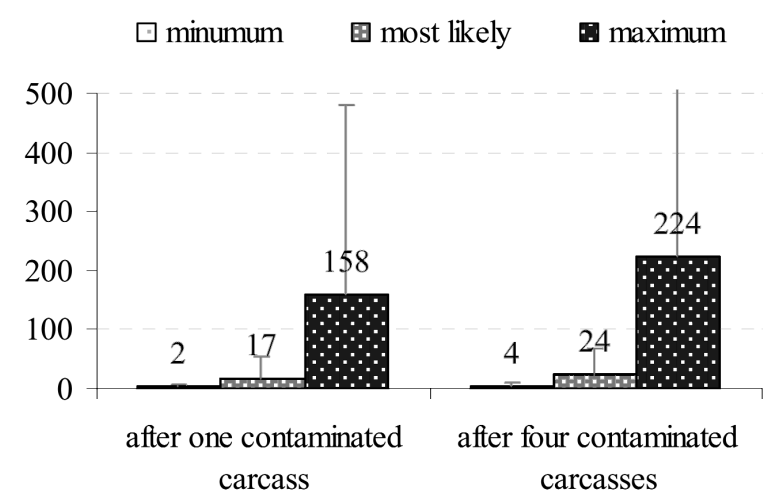

Figure 5. Number of Salmonella-free carcasses that can become (in) directly contaminated by the preceding contaminated carcass(es), ( $n=14$ respondents). performance of slaughterhouses and consequently the performance of the supply chain. Hence, to fulfil the demand for increased food safety and to be able to select the most cost-effective interventions, it is essential to gain more insight into this kind of knowledge.

\section{Discussion and conclusion}

Although the response rate of over 50\% was good, many respondents did not answer all the questions in the survey. Some reasons were given for this in Section 4. To determine and rank possible interventions, a survey among experts is a useful tool. However, to compare different categories of respondents, more respondents per category are needed than were available in this research. Including experts from more countries could solve this problem, as there was in this case a shortage of experts available in each country. The disadvantage of this solution is that the structure of the pork supply chain differs largely between countries. In new research the decision of whether or not to include more countries will depend on the number of experts available in a country per category and on the specific supply chain under investigation.

The aims of the survey of experts were to determine and rank management interventions to reduce the introduction and spread of Salmonella in the pork supply chain and to compare the opinions of experts from different countries and backgrounds.

The ranking of the management interventions in the primary stages shows that most of the emphasis is placed on reducing or preventing the spread of Salmonella within the farm. At the transport, lairage and slaughtering stages, the emphasis was on preventing cross-contamination. Two stages in the chain (finishing and slaughtering) are expected to be able to improve the food safety of pork with respect to Salmonella most effectively. Some management interventions such as logistic slaughtering have a large impact on the organisation of the entire pork supply chain. In these cases co-operation between supplier and buyer is essential and there is a possibility of joint investments. Before participants in a chain can introduce such co-operation, insight is needed into the exact interventions that are possible per stage. This insight is offered by this paper.

As could be expected, there is wide variation among respondents concerning the estimation of parameters about the course of infection and contamination. Knowledge about these parameters is still limited and further research should focus on the course of infection in practice.

The differences between respondents from the Netherlands and Denmark were small. Since the numbers of Danish respondents with Animal production or Retail \& Policy backgrounds was limited ( $n=2$ and $n=4)$, the Danish results 
were mainly determined by the Research group. The differences in the opinions of respondents from different backgrounds (Animal production, Retail \& Policy and Research) can mainly be seen in the relative importance attached to certain management interventions. Respondents from the Research group seem to attach most importance to interventions that are presented in recent literature, such as feeding non-heated grains, the dilemma of feed withdrawal before transportation and shortening waiting times at the lairage. The other respondents attached more importance to more general interventions, such as hygiene. With respect to co-operation and fine tuning processes in the pork supply chain, evaluations such as the one presented in this paper are important. In this case, the evaluation focussed on interventions related to one specific aspect of food safety. For all such issues in which multiple stages of a supply chain are involved, a solid basic knowledge about the conditions and consequences for each stage are necessary. The perceptions of participants in different stages can differ, which is important to know before initiating co-operation between stages.

\section{Acknowledgements}

The authors would like to thank Danilo M.A. Lo Fo Wong from the Danish Veterinary Laboratory for his contribution in selecting Danish experts. The authors thank all respondents for completing the survey. The research was co-financed by Agro Chain Competence in the Netherlands, Nutreco and Nedap Agri.

\section{References}

Alban, L., H. Stege and J. Dahl, 2002. The new classification system for slaughter-pig herds in the Danish Salmonella surveillanceand-control program. Preventive Veterinary Medicine 53, 133146

Anonymous, 1997. EU/US Discussions on veterinary equivalence agreement. Europe, Magazine of the European Union. No. 16/97

Anonymous, 2001. Livestock, Meat and Eggs in the Netherlands. Product boards of Livestock, Meat and Eggs.

Berends, B.R., F. Van Knapen, D.A.A. Mossel, S.A. Burt and J.M.A. Snijders, 1998. Impact on human health of Salmonella spp. on pork in the Netherlands and the anticipated effects of some currently proposed control strategies. International Journal of Food Microbiology, 44(3), 219-229

Borch E., T. Nesbakken and H. Christensen, 1996. Hazard identification in swine slaughter with respect to foodborne bacteria. International Journal of Food Microbiology 30, 9-25

CBS, 2002. Statistics Netherlands, Voorburg/Heerlen. Available at www.cbs.nl/en/
Christopherson, G. and E. Coath, 2002. Collaboration or Control in Food Supply Chains: Who Ultimately Pays the Price? In: Trienekens, J.H. and S.W.F. Omta (eds.) Paradoxes in Food Chains and Networks, Proceedings of the $5^{\text {th }}$ International Conference on Chain and Network Management in Agribusiness and the Food Industry. Wageningen Academic Publishers, the Netherlands Chopra, S. and P. Meindl, 2001. Supply Chain Management: Strategy, Planning, and Operation. Prentice-Hall, Inc., Upper Saddle River, New Jersey. 457pp

Davies R.H. and C. Wray, 1997. Distribution of salmonella contamination in ten animal feedmills. Veterinary Microbiology 51, 159-169

Dijkhuizen, A.A. and R.S. Morris, 1997. Animal Health Economics; principles and applications, University of Sydney, Australia

Frerichs G. and P. Venturini, 2002. Opinion of the European Economic and Social Committee on the Proposal for a directive of the European Parliament and of the Council on the monitoring of zoonoses and zoonotic agents. CES191/2002 - 2001/01760177 (COD) EN/o

Isaacson, R.E., R.M. Weigel, L.D. Firkins, P. Bahnson, 1999a. The effect of feed withdrawal on the shedding of Salmonella Typhimurium by swine. In: Bahnson, P.B. (ed.), Proceedings of the $3^{\text {rd }}$ International Symposium on the Epidemiology and Control of Salmonella in Pork, Washington, D.C., 282-284

Isaacson, R E; L.D. Firkins, R.M. Weigel, F.A. Zuckermann, and J.A. DiPietro, 1999b. Effect of transportation and feed withdrawal on shedding of Salmonella typhimurium among experimentally infected pigs. American Journal of Veterinary Research 60 (9) $1155-1158$

Jørgensen, L., J. Dahl and A. Wingstrand, 1999. The effect of feeding pellets, meal and heat treatment on the salmonella-prevalence in finishing pigs. In: Bahnson, P.B. (Ed.), Proceedings of the $3^{\text {rd }}$ International Symposium on the Epidemiology and Control of Salmonella in Pork, Washington, D.C. pp 308-312

Lammerding, A.M. and A. Fazil, 2000. Hazard identification and exposure assessment for microbial food safety risk assessment. International Journal of Food Microbiology, 58(3), 147-157

Reardon, T. and E. Farina, 2002. The rise of private food quality and safety standards: illustrations from Brazil. International Food and Agribusiness Management Review 4, 413-421

Rostagno M., S. Hurd, J. McKean, C. Ziemer, J. Gailey and R. Leite, 2001. Abattoir holding pens as a source of Salmonella for swine. In: Van der Wolf, P.J. (ed.), Proceedings of the $4^{\text {th }}$ International Symposium in the Epidemiology and Control of Salmonella and other Foodborne Pathogens in Pork, Leipzig, Germany, pp. 103105

Stege H., T.K. Jensen, K. Møller, P. Bækbo and S.E. Jorsal, 2001. Risk factors for intestinal pathogens in Danish finishing pig herds. Preventive Veterinary Medicine 50, 135-164 
Summerhill W.R. and C.L. Taylor, 1992. Obtaining Response to a Mail Questionnaire. Bulletin PE-19, Program and Organizational Department, Florida Cooperative Extension Service, Institute of Food and Agricultural Sciences, University of Florida

Swanenburg, M., 2000. Salmonella in the pork production chain: sources of Salmonella on pork. Thesis University of Utrecht, ADDIX, Wijk bij Duurstede, the Netherlands

Van der Wolf, P.J., 2000. Salmonella in the pork production chain: feasibility of Salmonella-free pig production. Thesis University of Utrecht, ADDIX, Wijk bij Duurstede, the Netherlands

Van Pelt, W. and S.M. Valkenburgh (eds.) 2001. Zoonoses and zoonotic agents in humans, food, animals and feed in the Netherlands. Available at www.keuringsdienstvanwaren.nl

Van Winsen R.L., 2001. Contribution of fermented feed to porcine gastrointestinal microbial ecology: influence on the survival of Salmonella. Thesis University of Utrecht, ADDIX, Wijk bij Duurstede, the Netherlands

Ziggers, G.W. and J. Trienekens, 1999. Quality assurance in food and agribusiness supply chains: Developing successful partnerships. International Journal of Production Economics 60-61, 271-279 


\section{Appendix}

Statements: All statements were presented to the Dutch respondents; statements marked with an asterisk $\left({ }^{*}\right)$ were presented to the Danish respondents.

1. Salmonella typhimurium is the most common Salmonella type in pigs.

2. The characteristics of Salmonella typhimurium can be used for studies about Salmonella in pigs.

3. A Salmonella infection is sub-clinical in pigs.

4. * Salmonella infections do not influence the production results of finishing pigs.

5. * After the infectious period a pig remains (temporarily) a carrier, e.g. in intestines or lymph nodes

6. * After the carrier period a pig remains (temporarily) serologically positive.

7. * A pig's sensitivity to Salmonella does not depend on its race, weight or sex.

8. * After a pig has gone through an infection, it is less sensitive to a new Salmonella infection.

9. * The course of a Salmonella infection can be represented as in Figure 2.

10. Only if a pig starts shedding does it move from state S1 to I1, otherwise it remains in state S1.

11. Not all pigs go through an infection at the same rate; in other words, some pigs shed longer or remain longer in the carrier state.

12. A pig is serologically positive if the antibodies are detectable by the standard ELISA test.

13. * The infectivity of infectious pigs is about equal in states I1, I2 and I3.

14. In each stage three infection routes can be distinguished: a) directly by way of an infective pig in a group within a compartment, b) indirectly by way of an infective pig at the farm or firm and c) through external sources such as feed, visitors, materials etc..

15. The infection rate within a compartment depends on the number of infective pigs in that compartment.

16. The infection rate within a farm or firm depends on the number of infective pigs in that farm or firm.

17. Pigs from a Salmonella-free farm are at risk during transport of catching an infection of Salmonella bacteria that are present in the truck from earlier transported pigs.

18. * All carrier animals become infectious during transportation (i.e. start shedding).

19. During transportation and in the lairage the number of infectious animals can remain the same or increase; it can not decrease.

20. During transportation and in the lairage the serological status of a pig remains the same.

21. In the lairage a pig can become infected by bacteria present in the lairage from pigs held their earlier or by the socalled 'house-flora' in the lairage.

22. * The greater the number of infectious pigs unloaded in the lairage, the higher the risk will be for susceptible pigs to become infected.

23. * Every pig can end up as a bacteria-free carcass at the slaughterline.

24. During the slaughtering process a pig/carcass can become contaminated by a) the so-called 'house-flora', b) by bacteria from pigs slaughtered earlier that day and c) by bacteria from external sources such as employees, materials.

25. * More contaminated pigs slaughtered in succession will result in a higher contamination risk to Salmonella-free pigs

26. * An uncontaminated carcass reduces the contamination risk for the following carcass. 